\title{
A Single Dose of Antibiotics in Laparoscopic Appendicectomy
}

\author{
B. Vijay ${ }^{\circledR}$, Vadala Satish Chandra Reddy ${ }^{\circledR}$ \\ Assistant Professor, Department of General Surgery, Bhaskar Medical College, Yenkapally, Moinabad, Ranga Reddy District, Telangana, India.
}

\section{Abstract}

Background: Single or multiple-dose regimens of antibiotics may rely on the patient's medical situation and the patient's susceptibility to infection. The present study was therefore planned to evaluate the effectiveness and outcomes of the single dose of antibiotics in patients undergoing laparoscopic appendicectomy. A simple, safe, and non-toxic drug is used for avoiding or eradicating contamination with a certain microorganism. Materials and Methods: The retrospective case study was conducted in Department of General Surgery, Bhaskar Medical College, Yenkapally, Moinabad, Ranga Reddy Dist., Telangana, India from March 2017 -February 2018 among 50 patients scheduled for laparoscopic appendicectomy. Laparoscopic appendicectomy patients were divided into two groups, one group of 30 patients received single dose pre-operative antibiotics and the other group of 20 patients received multiple doses of antibiotics. Results: Out of 50 patients, majority $84 \%$ were males and $16 \%$ were females. Out of 50 patients, 8 patients had SSI. Out of 50 patients, the majority $76 \%$ of the patients reported on day 2 and only $24 \%$ reported on day 1 of appendicectomy. 29 patients were discharged after a day stay in the hospital, $93 \%$ belonged to the single-dose group and 5\% belonged to the multiple-dose group. The remaining 21 patients were discharged on day 2 . The majority $95 \%$ belonging to the multiple-dose group were discharged on day 2 and $7 \%$ belonging to the single-dose group were discharged on day 2 as they have been kept under observation for infection. Conclusion: For basic, uncomplicated acute appendicitis, single dose of prophylactic antibiotics will help in cases of laparoscopic appendicectomy. There is no necessity for the post-operative administration of antibiotics.

Keywords: Appendicectomy, Antibiotics, Outcome, Complications, Surgical Site Infection

Corresponding Author: B. Vijay, Assistant Professor, Department of General Surgery, Bhaskar Medical College, Yenkapally, Moinabad, Ranga Reddy District, Telangana, India.

E-mail: drbvijayjanardhan@gmail.com

Received: 29 November 2019

Revised: 26 December 2019

Accepted: 11 January 2020

Published: 30 June 2020

\section{Introduction}

The appendix is a finger-like, blind-ended tube connected to the cecum, from which it develops in the embryo. ${ }^{[1]}$ The appendix is considered a vestigial organ. The human appendix averages $9 \mathrm{~cm}$ in length but can range from 5 to $35 \mathrm{~cm}$. The diameter of the appendix is $6 \mathrm{~mm}$ and more than $6 \mathrm{~mm}$ is considered a thickened or inflamed appendix. Appendicitis is an inflammation of the appendix. The potential origin of appendicitis is a blockage in the lining of the appendix that induces inflammation. The bacteria multiply quickly, so the appendix is inflamed, swollen and pus-filled. If not treated promptly, the appendix can rupture. Appendicitis can cause serious complications. Appendicectomy is regarded as the medical technique for extracting the appendix. Appendicectomy can be performed through open or laparoscopic surgery. When a laparoscopy appendectomy is done, three incisions are made, each approximately 1 to $2.5 \mathrm{~cm}$ long.An incision is made near the umbilicus or navel and one between the pubis and the umbilicus. The other incision is smaller on the right side of the lower abdomen. The doctor then slides into these incisions a camera and special equipment. The surgeon

checks the abdominal organs visually and recognizes the appendix using this device. The appendix is then freed fromall of its attachments and removed. The site of the cecumat which the appendix was previously connected is stitched. One of the incisions is used to remove the appendix. The instruments are removed and all the incisions are closed. The aim of the study is whether a single dose of antibiotics in laparoscopic appendicectomy is sufficient.

\section{Subjects and Methods}

Place of Study: Department of General Surgery, Bhaskar Medical College, Yenkapally, Moinabad, Ranga Reddy Dist., Telangana, India.

Type of Study: This was a retrospective case study of 50 cases of laparoscopic appendicectomy performed at the Department 
of General Surgery, Bhaskar Medical College with the use of single-dose pre-operative antibiotics.

Sample size: 50 .

Sampling Methods: Consecutive sampling.

\section{Inclusion Criteria}

All patients admitted with acute appendicitis undergoing emergency laparoscopic appendicectomy were considered eligible for this study.

\section{Exclusion Criteria}

Patients who had received antibiotics within 72 hours of admission or who were pregnant or immune compromised, subjects with diabetes, heart failure, anemia, and those patients found to have complicated appendicitis (gangrenous, perforated, appendicular mass or abscess) or normal appendix were excluded from the study.

Drug Used: Cefazolin $500 \mathrm{mg}$ and Metronidazole $500 \mathrm{mg}$ combined were administered to both groups.

\section{Statistical Methods}

Data were presented in the form of statistical tables and charts. SPSS software version 20 was used for statistical analysis.

\section{Ethical Approval:}

Approval was taken from the Institutional Ethics Committee prior to the commencement of the study.

Group 1 (Single dose): A single dose of antibiotics was given to all patients 1 hour prior to surgery.

Group 2 (Multiple doses): Three doses of antibiotics have been given to patients in the second group with 8 hours gap pre and post-operative.

\section{Results}

The information from the 50 patients were compiled and reported as follows.

\begin{tabular}{ll}
\hline \multicolumn{2}{|l}{ Table 1: Clinical profile of the patients } \\
\hline Parameters & No. of Cases \\
\hline Total No. of Cases & 50 \\
\hline Sex & \\
\hline Male & 42 \\
\hline Female & 8 \\
\hline Clinical Features & \\
\hline Fever & 6 \\
\hline Nausea & 8 \\
\hline Pain in right iliac fossa (RIF) & 36 \\
\hline
\end{tabular}

Out of 50 patients majority $84 \%$ were males and $16 \%$ were females.
In the clinical features or symptoms, the majority of the patients around $72 \%$ had pain in right iliac fossa (RIF), followed by nausea in $16 \%$ of the patients and the least symptom was fever in $12 \%$ of the patients.

\begin{tabular}{lll}
\hline \multicolumn{2}{l}{ Table 2: Condition of Appendix } \\
\hline $\begin{array}{l}\text { Condition of } \\
\text { Appendix }\end{array}$ & No. of Cases & SSI \\
\hline Normal & 28 & 4 \\
\hline Tip Adherent & 6 & 0 \\
\hline Tip inflamed & 12 & 2 \\
\hline Mildly inflamed & 4 & 2 \\
\hline Total & 50 & 8 \\
\hline
\end{tabular}

\section{Surgical Site Infection (SSI)}

Out of 50 patients, the condition of the appendix in 28 patients was normal.Inflamed tip was seen in 12 patients followed by adherent tip in 6 patients and the mildly inflamed appendix was seen in 4 patients.

Out of 28 normal appendix cases, 4 had SSI (Surgical SiteInfection) and out of 12 inflamed tip appendix, SSI was seen in 2 patients. Out of 4 mildly inflamed appendix patients, 2 had SSI.

Out of 50 patients, 8 patients had SSI.

\begin{tabular}{ll}
\hline Table 3: Swab culture of wound & \\
\hline Swab Culture of Wound & No. of Cases \\
\hline Negative & 6 \\
\hline Positive & 2 \\
Total & 8 \\
\hline
\end{tabular}

In 8 patients with SSI, swab culture of the wound was done out of which 6 patients were negative and 2 patients were positive for infection.

Table 4: No. of doseof antibiotics used in patient groups, single vs multiple

\begin{tabular}{|c|c|}
\hline Dose of Antibiotics used & No. of Patients \\
\hline Single & 28 \\
\hline Multiple & 20 \\
\hline Single converted to Multiple & 2 \\
\hline Total & 50 \\
\hline
\end{tabular}

Around 30 patients in group 1 received single dose and rest 20 in group 2 received multiple doses. Only 2 patients belonging to the single-dose group had to be administered multiple doses of antibiotics to treat the infection. 


\begin{tabular}{|c|c|c|c|c|}
\hline Feature & No. of Cases & & & \\
\hline & & $\begin{array}{l}\text { Group } \\
\text { (Single } \\
\text { dose) }\end{array}$ & 1 & $\begin{array}{l}\text { Group } 2 \\
\text { (Multiple } \\
\text { dose) }\end{array}$ \\
\hline \multicolumn{5}{|c|}{ Pre-operative Stay } \\
\hline Day 1 & 12 & 5 & & 12 \\
\hline Day 2 & 38 & 25 & & 8 \\
\hline \multicolumn{5}{|c|}{ Post-operative Stay } \\
\hline Day 1 & 40 & 28 & & 1 \\
\hline Day 2 & 10 & 2 & & 19 \\
\hline
\end{tabular}

Out of 50 patients, the majority $76 \%$ of the patients reported on day 2 and only $24 \%$ reported on day 1 of appendicectomy.

Day 1 post-operative: Out of 50 patients, 29 patients were discharged after a day's stay in the hospital, $93 \%$ belonged to the single-dose group and 5\% belonged to the multiple-dose group.

Day 2 post-operative: Remaining 21 patients were discharged on day 2 . The majority $95 \%$ belonging to multiple-dose group were discharged on day 2 and $7 \%$ belonging to the single-dose group were discharged on day 2 as they have been kept under observation for infection

\section{Discussion}

Laparoscopic surgeries are more accepted than conventional surgeries, because of its following advantages of reduced scope of infection, reduced post-operative pain, reduced hospital stay and quick rehabilitation. Not many studies have been carried out in patients with laparoscope based appendicectomies on the effectiveness of single dose prophylactic antibiotics since most studies have included either open or open as well as a laparoscopic procedure.

Thus, in this research, the effectiveness of the single dose prophylactic antibiotics was better understood by only undertaking laparoscopic appendicectomy cases. Appendicitis is more prevalent in men than in women. The most common symptom of acute appendicitis is right iliac fossa discomfort, the second most common is nausea and the least frequent is fever.

The most common problem after appendicectomy is surgical site infection. ${ }^{[2,3]}$ The Center for Disease Control and Prevention (CDC) also identified basic guidelines for surgical site infections. Throughout laparoscopic surgery, the risk of infection occurs when the skin becomes incised and the first natural layer is removed, but the highest risk of infection is at the moment of tissue processing, which may also contribute to post-operative infection. Many surgical diseases at the site are minor while they contribute significantly to surgical morbidity and mortality. ${ }^{[4,5]}$ Because laparoscopic incisions are smaller than those of traditional open surgery, the former has a decreased frequency of SSIs. Wound infection can cause serious complications such as burst abdomen, incisional hernia, necrotic fasciitis and septicemia unless controlled. A single efficient non-toxic drug is used for the reduction or eradication of an infection with a particular microorganism. In order to prevent surgical infection or treating wound, single or multiple doses of antibiotics are required. ${ }^{[6]}$

Along with this pre-operative planning for the patient, avoidance of post-operative wound infection through aseptic treatment and cautious operation are equally necessary. For clean contaminated cases, antimicrobial prophylaxis is advised. ${ }^{[7]}$ Reducing post-operative hospital stay helps reduce the chance of wound infection. Surgical site inflammation in $16 \%$ of cases was reported, with only $4 \%$ positive and $12 \%$ negative in swab culture. $60 \%$ of the patients received a single dose and the rest $40 \%$ were administered multiple doses of antibiotics. 93\% patients who received a single dose of antibiotics were discharged on day 1 and only $5 \%$ were of multiple dose antibiotics patientsdischarged following no complications on day $1.95 \%$ who were administered multiple doses of antibiotics were discharged on day 2 compared to $7 \%$ of the single-dose antibiotics group. $7 \%$ of the cases of the single-dose group had to be given multiple doses of antibiotics for treating the infection. So it has to be noted that the group who were administered a single dose of antibiotics pre-operatively had reduced post-operative stay, the lesser financial burden on the patient and lesser side effects compared to the group with multiple doses of antibiotics.

Irvin et al noted that the dehiscence and herniation of infected wounds have been seen more and it is often advisable to prevent wound infections when necessary, given the increased occurrence of such complications. ${ }^{[8]}$ Bucknall

et al. also reported that wound inflammation is an important factor in the abdominal burst and hernia. ${ }^{[7]}$ The incidence of medical risks, including wound diseases, in appendicectomy cases, is usually very low. ${ }^{[7]}$ Patients usually undergo longterm expensive post-operative parenteral antibiotics. The rationale for this procedure is the belief that wounds may lead to catastrophic complications. Such long-term treatment of antibiotics is excessive, can enhance antibiotic resistance, can have side effects linked to antibiotics and on the other hand, it considerably raises the financial burden on the patient. ${ }^{[9,10]}$

\section{Conclusion}

In cases of laparoscopic appendicectomy, a single dose of prophylactic pre-operative antibiotics would be appropriate for basic, uncomplicated acute appendicitis. In these situations, the post-operative administration of antibiotics would not be necessary. 


\section{References}

1. Wei HB, Huang JL, Zheng ZH, Wei B, Zheng F, Qiu WS. Laparoscopic versus open appendectomy: a prospective randomized comparsion. Surg Endosc. 2010;24(2):266-275.

2. Danwang C, Bigna JJ, Tochie JN, Mbonda A, Mbanga CM, Nzalie RNT, et al. Global incidence of surgical site infection after appendectomy: a systematic review and meta-analysis. BMJ Open. 2020;10(2):e034266. doi:10.1136/bmjopen-2019034266.

3. Danwang C, Mazou TN, Tochie JN, Nzalie RNT, Bigna JJ. Global prevalence and incidence of surgical site infections after appendectomy: a systematic review and meta-analysis protocol. BMJ Open. 2018;8(8):e020101. doi:10.1136/bmjopen-2017020101.

4. Leaper DJ, van Goor H, Reilly J, Petrosillo N, Geiss HK, Torres AJ, et al. Surgical site infection - a European perspective of incidence and economic burden. Int Wound J. 2004;1(4):247273. Available from: https://dx.doi.org/10.1111/j.1742-4801. 2004.00067.x. doi:10.1111/j.1742-4801.2004.00067.x.

5. Dipiro JT, Martindale RG, Bakst A, Vacani PF, Watson P, Miller MT. Infection in surgical patients: Effects on mortality, hospitalization, and postdischarge care. Am J Health-Syst Ph. 1998;55(8):777-781. Available from: https://dx.doi.org/10. 1093/ajhp/55.8.777. doi:10.1093/ajhp/55.8.777.

6. Kow L, Toouli J, Brookman J, McDonald PJ. Comparison of cefotaxime plus metronidazole versus cefoxitin for prevention of wound infection after abdominal surgery. World J Surg. 1995;19(5):680-686. Available from: https://dx.doi.org/10. 1007/bf00295902. doi:10.1007/bf00295902.
7. ASHP therapeutic guidelines on antimicrobial prophylaxis in surgery. ASHP Commission on Therapeutics. Clin Pharm. 1992;11(6):483-513.

8. Irvin TT, Stoddard CJ, Greaney MG, Duthie HL. Abdominal wound healing: a prospective clinical study. $\mathrm{Br}$ Med J. 1977;2(6083):351-352. Available from: https://dx.doi.org/10. 1136/bmj.2.6083.351. doi:10.1136/bmj.2.6083.351.

9. Meeks DW, Kao LS. Controversies in Appendicitis. Surg Inf. 2008;9(6):553-558. Available from: https://dx.doi.org/10. 1089/sur.2008.9954. doi:10.1089/sur.2008.9954.

10. Busuttil RW, Davidson RK, Fine M, Tompkins RK. Effect of Prophylactic Antibiotics in Acute Nonperforated Appendicitis. Ann Surg. 1981;194(4):502-509. Available from: https://dx.doi.org/10.1097/00000658-198110000-00013. doi:10.1097/00000658-198110000-00013.

Copyright: (C) the author(s), 2020. It is an open-access article distributed under the terms of the Creative Commons Attribution License (CC BY 4.0), which permits authors to retain ownership of the copyright for their content, and allow anyone to download, reuse, reprint, modify, distribute and/or copy the content as long as the original authors and source are cited.

How to cite this article: Vijay B, Reddy VSC. A Single Dose of Antibiotics in Laparoscopic Appendicectomy. Acad. J Surg. 2020;3(1):124-127.

DOI: dx.doi.org/10.47008/ajs/2020.3.1.27

Source of Support: Nil, Conflict of Interest: None declared. 